\title{
Color Evolution in Single Crystal Colored Cubic Zirconias With Annealing Atmosphere and Temperature
}

\author{
Jeongho Song, Yunyoung Noh, and Ohsung Song ${ }^{\dagger}$ \\ Department of Materials Science and Engineering, University of Seoul, Seoul 02504, Korea \\ (Received April 1, 2016; Revised May 16, 2016; Accepted May 16, 2016)
}

\begin{abstract}
Color change in single-crystal, yellow, red, purple, and colorless cubic zirconias (CZs) was investigated as a function of annealing in vacuum and air atmosphere at $800-1400^{\circ} \mathrm{C}$ for $30 \mathrm{~min}$, for development of a damascene process of plugging a precious metal paste at the elevated temperature. Coloring-element contents of the CZs were evaluated using WD-XRF, and the color change determined visually by naked eye, and using a digital camera and UV-Vis-NIR color analyzer. WD-XRF showed that all of the $\mathrm{CZs}$ had cubic-phase stabilizer elements and coloring elements. All CZs that underwent vacuum annealing exhibited a slight color change at $<900^{\circ} \mathrm{C}$, while their colors began to change to black at $1100^{\circ} \mathrm{C}$, and became opaque black at $1400^{\circ} \mathrm{C}$. After air annealing, there was almost no color change up to $1400^{\circ} \mathrm{C}$. Since red and purple $\mathrm{CZs}$ showed greater color difference (CD) values than the others, the degree of $\mathrm{CD}$ is likely to depend on the original color of the $\mathrm{CZ}$ due to the different stabilities of their coloring elements during annealing. Based on our results, it is suggested that annealing in air at $<900^{\circ} \mathrm{C}$ is advantageous, and assorted colored CZs can be used for precious metal damascene.
\end{abstract}

Key words : Cubic zirconia, Color difference, Annealing, WD-XRF, CIE Lab

\section{Introduction}

C ubic zirconia (CZ) is a single crystal ceramic mixed with a stabilization additive such as $\mathrm{Y}_{2} \mathrm{O}_{3}$ allowing the cubic structure of zirconia $\left(\mathrm{ZrO}_{2}\right)$ to be maintained in a low-temperature region, and is one of important ceramic materials used for oxygen sensor, high-temperature fuel cell, etc. ${ }^{1,2)}$ In addition, CZ has a high refractive index of 2.15, a high Mohs hardness value of 8.5, thus having suitable material property values for use as a jewelry material. ${ }^{3,4)}$ Accordingly, jewelries loaded with colorless CZs as simulant of diamond have been activated in domestic jewelry industry, and such products are accounting for about $24 \%$ of the total jewelry market.

Recently, not only diamond but also ruby, sapphire and emerald with the high values among colored gemstones are also substituted by colored CZs of red, blue, and green, etc. for utilization. ${ }^{6)}$ In examples for application places of such colored CZs, they are being utilized for commemoration rings accompanying graduation, commissioning as well as commemoration jewelries for winning various sports competitions.

As the consumers' needs are diversified recently, high value-added products with materialization of precious metal damascene patterns having initials and logo in the

\footnotetext{
${ }^{\dagger}$ Corresponding author: Ohsung Song

E-mail : songos@uos.ac.kr

Tel : +82-2-6490-2410 Fax : +82-2-6490-2404
}

upper part of $\mathrm{CZ}$ are being developed in addition to the products with simple loading of $\mathrm{CZ}{ }^{7)}$ To materialize precious metal patterns in the upper part of high-hardness CZ, such products are produced through annealing after coating of precious metal paste such as gold or silver onto the pattern groove of more than $300 \mu \mathrm{m}$ in depth which is engraved by a mask process beforehand. While the high-temperature annealing at $1000^{\circ} \mathrm{C}$ is required at this time, possibilities of discoloration upon such high-temperature annealing are being reported in the case of $\mathrm{CZ}$.

Li et $a l .^{8)}$ have reported a phenomenon where blackening of samples was accelerated with an increase in temperatures in the case of vacuum annealing under the temperature condition of $1000 \sim 1400^{\circ} \mathrm{C}$ for single crystal CZs with diversified colors, and they were returned to the original colors again upon follow-up annealing in air atmosphere. Shen et al. . $^{9}$ confirmed the discoloration phenomenon as a function of annealing time upon vacuum annealing at 1200 and $1400^{\circ} \mathrm{C}$ for colorless, yellow, and brown $\mathrm{CZs}$, and reported that this was a phenomenon due to decomposition of $\mathrm{Y}_{2} \mathrm{O}_{3}$ as a phase stabilizing element.

However, considering that the sintering temperatures for nano-class precious metal pastes of gold and silver were lowered to about $800^{\circ} \mathrm{C}$, there appear to be no quantitative reports on discoloration of colored $\mathrm{CZs}$ under a relatively low temperature condition of $800^{\circ} \mathrm{C}$.

Therefore, to prevent discoloration due to annealing process essential in realization of the damascene patterns on $\mathrm{CZ}$, annealing in the present study was conducted in vacuum and air atmosphere at $800 \sim 1400^{\circ} \mathrm{C}$ for the colored $\mathrm{CZ}$ 
single crystals for jewelries, and discoloration was checked for different annealing conditions.

\section{Experimental Procedure}

To check for discoloration as a function of annealing temperature and atmosphere for the colored $\mathrm{CZs}_{\mathrm{s}}, 4$ types of $\mathrm{CZ}$ samples of yellow, red, purple, and colorless with a size of $14 \times 12 \mathrm{~mm}$ subjected to emerald brilliant cutting were prepared as shown in Fig. 1. The relevant colors were selected where the red color is most widely used for commissioning rings of Korea Military Academy, and the purple color for commissioning rings of ROTC, while yellow and colorless stones were most universally employed as a diamond substitute.

For quantitative confirmation of the elements in the prepared CZ samples, wavelength-dispersive X-ray spectroscopy (WD-XRF, XRF-1700, Shimadzu Co.) analysis was performed. The analysis to check for the contents of coloring elements was conducted for each CZs by using Rh target under the analysis conditions of $40 \mathrm{kV}$ and $90 \mathrm{~mA}$.

For annealing in vacuum atmosphere, the samples were held for $30 \mathrm{~min}$ at the target temperatures of $800 \sim$ $1400^{\circ} \mathrm{C}$ with a temperature rise rate of $10^{\circ} \mathrm{C} / \mathrm{min}$ under the vacuum below $1.0 \times 10^{-2}$ torr in vacuum by using a vacuum annealing furnace (DE/KR 1706, Heraeus Co.), followed by air cooling, while annealing in air atmosphere by using an annealing furnace (SK1700 B30, Thermotechno Co.) was conducted under the same temperature and time conditions as those for annealing in vacuum atmosphere.

To check for the changes in CZ samples before and after annealing, a macro image analysis was conducted. After positioning $\mathrm{CZs}$ on the center part table of a diamond view

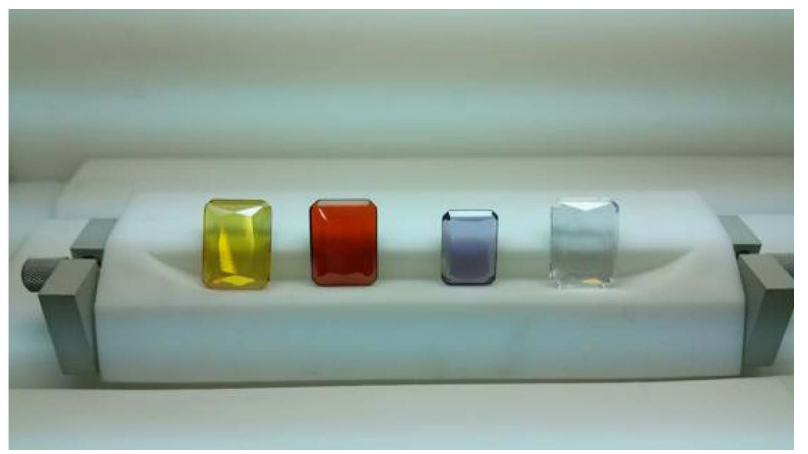

Fig. 1. Macro image of CZ reference samples (yellow, red, purple and colorless). box (DiamondLite, GIA Co.), photos were taken by using a digital camera (Galaxy A800, Samsung Co.).

To quantitatively check for the colors of $\mathrm{CZ}$ samples before and after annealing, UV-Vis-NIR (UV-3101PC, Shimadzu Co.) was employed. For the conditions at this time, a halogen light source was used at the wavelength range of $380 \sim 780 \mathrm{~nm}$, and the slit value was set at 20 , the scan speed at medium in the measurement range for absorptionreflection-wavelength of CZ. CIE Lab color indices were determined for the spectrum secured through this procedure by using the color analysis program embedded in the instrument. ${ }^{10)}$ At this time, $L$ value shows brightness, showing red $\sim$ green (the more red color for the more negative number and the greener color for the more positive number) in the case of $a$, and blue yellow (the bluer color for the more negative number and the more yellow color for the more positive number) in the case of $b$. The color difference $(\Delta E)$ was calculated as $\Delta E=\sqrt{\Delta L^{2}+\Delta a^{2}+\Delta b^{2}}$ by using the Lab indices. $^{11,12)}$

\section{Results and Discussion}

In Table 1, WD-XRF analysis results of CZs are shown per color. In all cases of the 4 types of $\mathrm{CZs}, \mathrm{Y}_{2} \mathrm{O}_{3}$ was confirmed to be contained as an added element with the purpose of stabilizing the main component of zirconia with a cubic structure. ${ }^{13)}$ Also, a minor amount of $\mathrm{HfO}_{2}$ reinforcing thermal shock resistance was found to be contained in all $\mathrm{CZs}^{14)}$

In the case of yellow, $\mathrm{BaO}$ and $\mathrm{Fe}_{2} \mathrm{O}_{3}$ were confirmed to act as a coloring element. These elements were in agreement with the coloring elements for yellow color reported by Guo et al. ${ }^{15)}$ On the other hand, $\mathrm{CeO}_{2}$ and $\mathrm{Ho}_{2} \mathrm{O}_{3}$ were confirmed to act as a coloring element for red, ${ }^{16)}$ and $\mathrm{Co}_{2} \mathrm{O}_{3}$ and $\mathrm{Fe}_{2} \mathrm{O}_{3}$ were contained as a coloring element for purple. In the case of colorless, however, trace amounts of $\mathrm{Cr}_{2} \mathrm{O}_{3}$ and $\mathrm{TiO}_{2}$ were contained in addition to $\mathrm{Y}_{2} \mathrm{O}_{3}$ and $\mathrm{HfO}_{2}$ the essential components of CZs without affecting colors. ${ }^{17}$

Figure 2 shows macro images of yellow, red, purple, and colorless CZs after annealing at $800 \sim 1400^{\circ} \mathrm{C}$ for $30 \mathrm{~min}$ in vacuum atmosphere The samples are treated at $25^{\circ} \mathrm{C}$ for reference.

In the case of vacuum annealing at $800^{\circ} \mathrm{C}$, the same colors as before annealing or annealing at $25^{\circ} \mathrm{C}$ were found. No change in colors by annealing at $800^{\circ} \mathrm{C}$ could be affirmed in the case of synthetic CZs in the present experiment, although inclusions are normally contained in natural gemstones and the inclusions expand by annealing so as to

Table 1. Chemical Composition of CZ Specimen by WD-XRF (wt\%)

\begin{tabular}{ccccccccccc}
\hline \multirow{2}{*}{ Eample } & $\mathrm{ZrO}_{2}$ & $\mathrm{Y}_{2} \mathrm{O}_{3}$ & $\mathrm{HfO}_{2}$ & $\mathrm{Cr}_{2} \mathrm{O}_{3}$ & $\mathrm{TiO}_{2}$ & $\mathrm{CeO}_{2}$ & $\mathrm{Ho}_{2} \mathrm{O}_{3}$ & $\mathrm{Co}_{2} \mathrm{O}_{3}$ & $\mathrm{Fe}_{2} \mathrm{O}_{3}$ & $\mathrm{BaO}^{2}$ \\
\hline yellow & 78.1357 & 18.7560 & 1.7865 & - & - & - & - & - & 0.0643 & 0.0972 \\
red & 80.7708 & 16.7353 & 1.8942 & - & - & 0.3496 & 0.1274 & - & - & - \\
purple & 81.0324 & 16.6918 & 1.9832 & - & - & - & - & 0.1382 & 0.0761 & - \\
colorless & 82.5562 & 15.3258 & 1.9172 & 0.0936 & 0.0540 & - & - & - & - & - \\
\hline
\end{tabular}




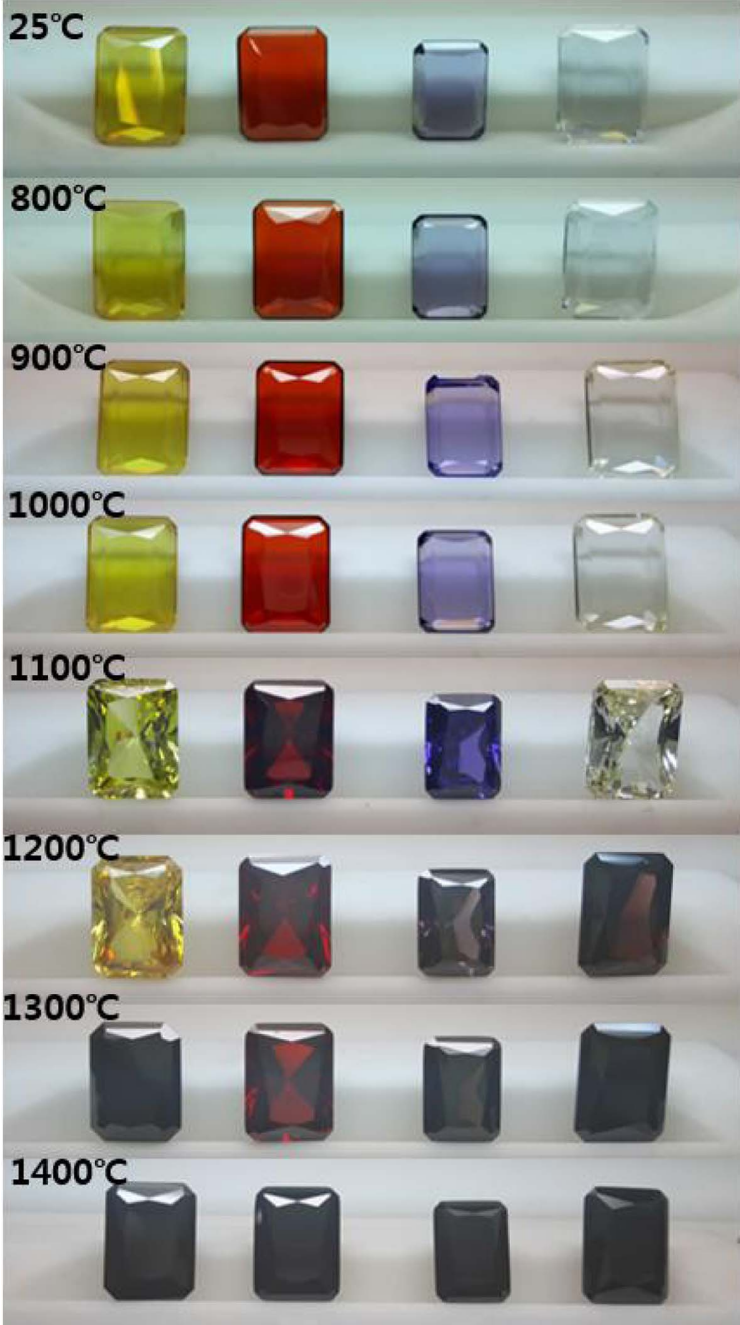

Fig. 2. Macro images of $\mathrm{CZ}$ after annealing at $25 \sim 1400^{\circ} \mathrm{C}$ in vacuum atmosphere.

cause discoloration, breakage, etc. Annealing at $900^{\circ} \mathrm{C}$ and $1000^{\circ} \mathrm{C}$, resulted in the similar colors as those from $800 \mathrm{C}$ annealing except that the edges of the colorless $\mathrm{CZ}$ became yellowish. Vacuum annealing at $1100^{\circ} \mathrm{C}$ resulted in the significant darkening of yellow, red and purple CZs. Colorless $\mathrm{CZ}$ was changed to a darker yellow color. In the case of $1200^{\circ} \mathrm{C}$ annealing, the yellow and red CZs were darkened further than those from $1100^{\circ} \mathrm{C}$ annealing. In the purple case, not only the color was darkened but also the inherent chroma was lowered and the color became close to dark grey. Colorless $\mathrm{CZ}$ became dark brown. By $1300^{\circ} \mathrm{C}$ annealing, yellow, purple, and colorless $\mathrm{CZ}$ became dark and indistinguishable. Red CZs became darker than from $1200^{\circ} \mathrm{C}$ annealing. Finally, $1400^{\circ} \mathrm{C}$ annealing turned all 4 color type $\mathrm{CZs}$ indistinguishably blackened. Transmission of strong back light was not observable and was not improved by the surface polishing. They cannot be used as jewel material.

In short, there was no visual color change by vacuum annealing at $800^{\circ} \mathrm{C}$ and the discoloration of the colorless $\mathrm{CZ}$ started at $900^{\circ} \mathrm{C}$. Substantial discoloration of all colored CZs started at $1000^{\circ} \mathrm{C}$ and complete blackening occurred at higher temperature annealing.

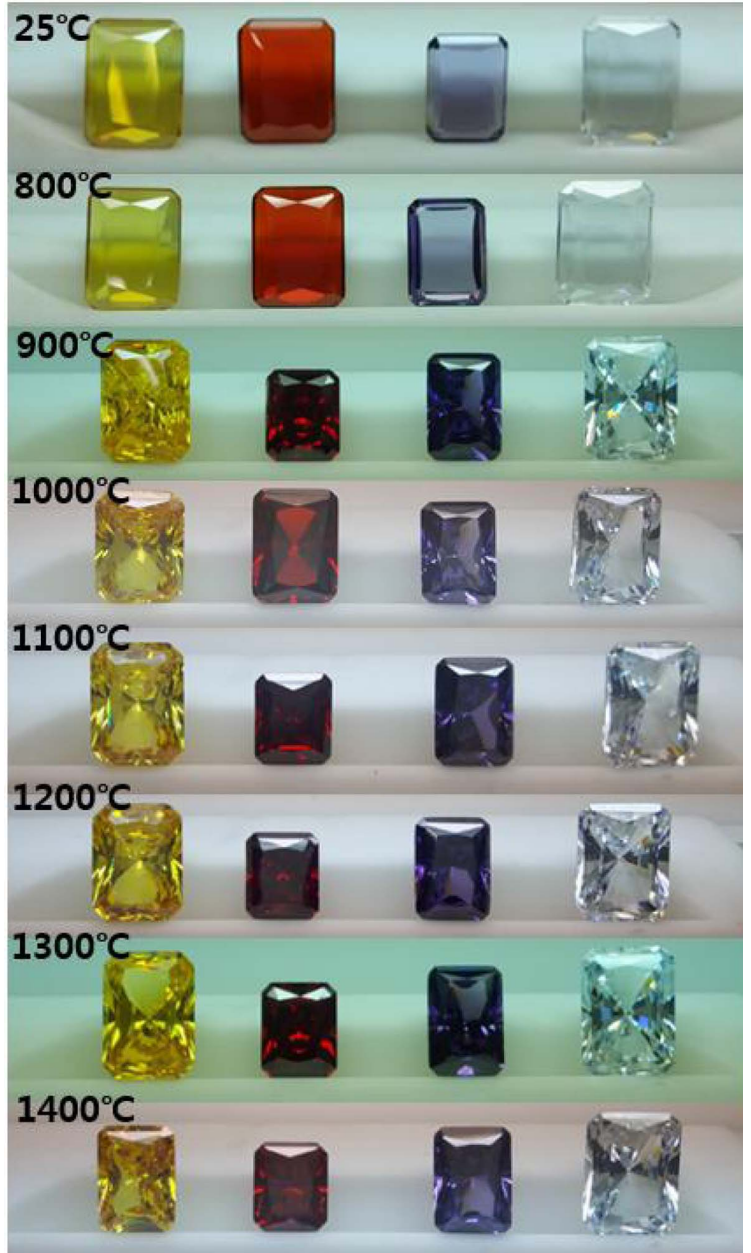

Fig. 3. Macro images of $\mathrm{CZs}$ after annealing at $25 \sim 1400^{\circ} \mathrm{C}$ in air atmosphere.

Figure 3 shows macro images after annealing in air atmosphere, similarly as in vacuum atmosphere shown in Fig. 2 discussed above. Almost no visual change in colors of $\mathrm{CZ}$ was found at all annealing temperatures in air unlike the vaccuum annealing where substantial darkening occurred at $1100^{\circ} \mathrm{C}$ and blackening at $1300^{\circ} \mathrm{C}$. Such results suggest that the air atmosphere should be more suitable than the vacuum atmosphere for damascene operation.

Table 2 shows Lab color indices of CZs per color as a function of annealing temperature in vacuum atmosphere.

In the case of yellow $\mathrm{CZ}$, while the values of each index up to $1000^{\circ} \mathrm{C}$ were similar almost without a change in colors, the index value of $b$ related to yellow from $1100^{\circ} \mathrm{C}$ was subsequently lowered to 40.4 as compared with 65.7 at $1000^{\circ} \mathrm{C}$, thus quantitatively confirming that the chroma of yellow color was dropped. Subsequently, the $L$ value related to brightness was lowered from that of $1300^{\circ} \mathrm{C}$ annealing and occurrence of blackening was shown by the $a, b$ values approaching.

In the case of red CZ, no large difference in $L$ values was shown for all annealing temperatures, which suggests red $\mathrm{CZ}$ originally has a dark red color originally had a dark red 
color. However, progression of the darkening is indicated in the $a$ value related to red color which approached 0 above $1200^{\circ} \mathrm{C}$

In the case of purple $\mathrm{CZ}$, all showed similar $L$ and $a$ values for all annealing temperatures. The $b$ value showed a negative number close to blue, which then approached 0 above $1200^{\circ} \mathrm{C}$ due to the blackening.

In the case of colorless $\mathrm{CZ}$, a large reduction in $L$ values resulting from the blackening was indicated with increasing annealing temperatures. The $b$ value was gradually increased above $900^{\circ} \mathrm{C}$ in accordance with the yellow tinting in the edge part shown in the macro image analysis. It decreases to 0 above $1000^{\circ} \mathrm{C}$, however, due to the blackening.

Thus, drastic change in Lab indices shows quantitatively the darkening of $\mathrm{CZs}$ occurring above $1100^{\circ} \mathrm{C}$ in vaccum, which was in agreement with the report by $\mathrm{Li}$ et $a l^{8)}$ that the color of $\mathrm{CZ}$ was blackened at high temperatures above $1200^{\circ} \mathrm{C}$ upon vacuum annealing.

In Table 3, Lab color indices of CZs resulting from annealing in air atmosphere are shown for different annealing temperatures. In the case of yellow $\mathrm{CZ}$, all showed similar $L$ values irrespective of annealing temperatures, and the $b$ value related to yellow color did not show large change. In the case of red CZ, similar values of brightness and the $a$ index related to red color were shown for all annealing temperatures. Similar results were found for the purple CZ. Colorless CZ showed a higher $L$ value than the colored CZ as it was close to white color. Similar Lab indices for all annealing temperatures were found, which is consistent with the visual analysis.

Consequently, in the case of air atmosphere, in contrast to the vacuum atmosphere, all showed similar color indices so that no large change in colors could be sensed consistent with the visual analysis results described earlier.

Figure 4 represents a graph showing color differences of the samples annealed for $30 \mathrm{~min}$ at temperatures 800 $1400^{\circ} \mathrm{C}$, with respect to Lab color indices of the sample annealed at $25^{\circ} \mathrm{C}$ using the numerical values of Tables 2 and 3.

Figure 4(a) is the graph showing color differences for the $\mathrm{CZ}$ samples subjected to annealing in vacuum environment. In the case of yellow $\mathrm{CZ}$, visual differentiation was possible as color differences of more than 20 exist above $1100^{\circ} \mathrm{C}$ although almost no change in color indices are indicated up to $1000^{\circ} \mathrm{C}$. The increase in the Lab color differences above $1100 \mathrm{C}$ for the red $\mathrm{CZ}$ and above $1000 \mathrm{C}$ for the colorless CZ can be related to the drastic color change in the visual analysis. In the case of purple $\mathrm{CZ}$, the color differences are small as around 11 in average for all temperatures. The results indicate the change in chroma after annealing, since the original reference sample has a high chroma and a low brightness.

The drastic blackening phenomenon in vacuum atmosphere, it was considered to be the phenomenon occurring as there was deviation from the stable coloring position with lowering of oxygen partial pressures of the surroundings since $\mathrm{Y}_{2} \mathrm{O}_{3}$ and coloring elements contained as additives

Table 2. Lab Color Index and Color Difference of CZs after Annealing in Vacuum Atmosphere

\begin{tabular}{ccccc}
\hline $\begin{array}{c}\text { Color } \\
\text { Temp. }\left({ }^{\circ} \mathrm{C}\right)\end{array}$ & Yellow & Red & Purple & Colorless \\
\cline { 2 - 5 } & $L / a / b$ & $L / a / b$ & $L / a / b$ & \multicolumn{1}{c}{ / $b$} \\
\hline 25 & $64.1 /-11.2 / 61.3$ & $35.6 / 48.1 / 48.9$ & $37.0 /-1.9 /-12.1$ & $92.4 /-6.6 /-4.2$ \\
800 & $65.0 /-12.1 / 62.3$ & $34.6 / 47.6 / 47.0$ & $38.1 /-2.1 /-13.4$ & $91.0 /-8.2 /-2.0$ \\
900 & $63.1 /-7.1 / 62.3$ & $37.0 / 54.1 / 51.0$ & $35.7 / 1.2 /-16.4$ & $62.0 /-5.9 / 21.2$ \\
1000 & $65.7 /-14.4 / 65.7$ & $35.3 / 50.0 / 42.4$ & $39.6 / 6.3 /-19.9$ & $60.2 /-2.9 / 10.2$ \\
1100 & $55.2 /-16.2 / 40.4$ & $35.2 / 23.2 / 6.9$ & $24.9 / 4.1 /-18.6$ & $39.1 / 11.6 / 4.6$ \\
1200 & $62.4 /-3.8 / 44.9$ & $42.3 / 42.9 / 18.4$ & $29.2 / 6.9 /-9.6$ & $23.3 /-2.2 /-3.9$ \\
1300 & $24.7 /-2.1 /-5.6$ & $37.1 / 18.8 / 4.1$ & $34.0 / 2.0 / 3.6$ & $19.4 / 0.6 / 0.7$ \\
1400 & $24.1 / 0.1 / 0.0$ & $27.0 / 0.1 /-2.0$ & $23.1 / 0.1 /-1.1$ & \\
\hline
\end{tabular}

Table 3. Lab Color Index and Color Difference of CZs after Annealing in Air Atmosphere

\begin{tabular}{ccccc}
\hline $\begin{array}{c}\text { Color } \\
\text { Temp. }\left({ }^{\circ} \mathrm{C}\right)\end{array}$ & Yellow & Red & Purple & Colorless \\
\cline { 2 - 5 } & $L / a / b$ & $L / a / b$ & $L / a / b$ & \multicolumn{1}{c}{ / $b$} \\
\hline 25 & $64.1 /-11.2 / 61.3$ & $35.6 / 48.1 / 48.9$ & $37.0 /-1.9 /-12.1$ & $92.4 /-6.6 /-4.2$ \\
800 & $62.6 /-13.0 / 62.0$ & $34.0 / 48.7 / 46.4$ & $37.0 /-1.9 /-12.1$ & $95.3 /-7.0 /-2.7$ \\
900 & $61.9 /-5.7 / 63.1$ & $33.9 / 53.1 / 46.7$ & $32.3 / 3.5 /-7.2$ & $93.7 /-9.5 /-2.2$ \\
1000 & $65.7 /-10.2 / 36.0$ & $41.0 / 38.0 / 26.2$ & $35.0 / 6.7 /-16.9$ & $85.4 /-3.6 /-9.9$ \\
1100 & $67.3 /-9.6 / 53.7$ & $26.5 / 43.3 / 29.7$ & $37.9 / 9.2 /-19.2$ & $90.9 /-1.7 /-5.6$ \\
1200 & $64.6 /-10.1 / 56.0$ & $37.9 / 56.0 / 48.0$ & $36.7 / 12.2 /-24.9$ & $94.6 / 0.3 / 0.9$ \\
1300 & $61.1 /-19.1 / 57.9$ & $33.4 / 54.9 / 42.4$ & $39.6 / 6.2 /-19.1$ & $91.6 /-10.6 /-2.4$ \\
1400 & $62.3 /-9.7 / 50.3$ & $35.6 / 39.8 / 21.3$ & $41.2 / 8.0 /-19.2$ & $85.7 / 1.1 /-2.2$ \\
\hline
\end{tabular}


were becoming unstable as a result of annealing in vacuum atmosphere as previously reported by Shen et al. ${ }^{9)}$

Figure 4(b) represents a graph showing color differences for $\mathrm{CZ}$ samples as a function of annealing temperature in air atmosphere. All of the 4 colors showed color differences less than the maximum of 30 in all annealing sections, relatively smaller in comparison with the annealing in vacuum atmosphere. The inherent colors of CZs were considered to be maintained without the blackening phenomenon since the additives were positioned in a relatively stable manner even if temperatures were raised due to the annealing under the situation where a sufficient amount of $\mathrm{O}^{2-}$ was supplied unlike the annealing in vacuum atmosphere.

In the case of red and purple CZs, relatively large color differences in Lab indices are indicated in comparison with the colorless and yellow cases. Considering the WD-XRF composition analysis results shown earlier, this meant that the coloring elements of $\mathrm{CeO}_{2}, \mathrm{Ho}_{2} \mathrm{O}_{3}, \mathrm{Co}_{2} \mathrm{O}_{3}, \mathrm{Fe}_{2} \mathrm{O}_{3}$ became relatively unstable so as to be capable of inducing a fine change in colors as the temperature was raised even in air atmosphere.

According to such results, limitation of annealing temperatures to below $900^{\circ} \mathrm{C}$ in air atmosphere or employment of colorless, yellow CZ having excellent thermal stability are recommended, when damascene process is implemented on the colored $\mathrm{CZ}$ matrix.

\section{Conclusions}

To realize precious metal damascene patterns, color changes in $\mathrm{CZ}$ were investigated in vacuum and air atmosphere as a function of annealing temperature. All of yellow, red, purple and colorless $\mathrm{CZs}$ contained $\mathrm{ZrO}_{2}, \mathrm{Y}_{2} \mathrm{O}_{3}$, $\mathrm{HfO}_{2}$. It was found that the coloring elements of $\mathrm{BaO}$ and $\mathrm{Fe}_{2} \mathrm{O}_{3}$ were contained in the case of yellow $\mathrm{CZ}, \mathrm{CeO}_{2}$ and $\mathrm{Ho}_{2} \mathrm{O}_{3}$ in the case of red $\mathrm{CZ}, \mathrm{Co}_{2} \mathrm{O}_{3}$ and $\mathrm{Fe}_{2} \mathrm{O}_{3}$ in the case of purple CZ. While almost no change in colors was observed below $900^{\circ} \mathrm{C}$ in vacuum atmosphere, blackening started at $1100^{\circ} \mathrm{C}$ for all colors, and complete change to black color was obsered at $1400^{\circ} \mathrm{C}$. Upon annealing in air atmosphere, the color differences for colorless and yellow cases were smaller than those for red and purple cases, although no large change occurred for all annealing conditions. Consequently, colored CZs should be treated below 900C in air atmosphere to avoid color change. Yellow and colorless CZ can be employed without discoloration for damascene process at higher temperature.

\section{Acknowledgments}

This work (Grants No. C0300244) was supported by Business for Cooperative R\&D between Industry, Academy and Research Institute funded by Korea Small and Medium Business Administration in 2015.

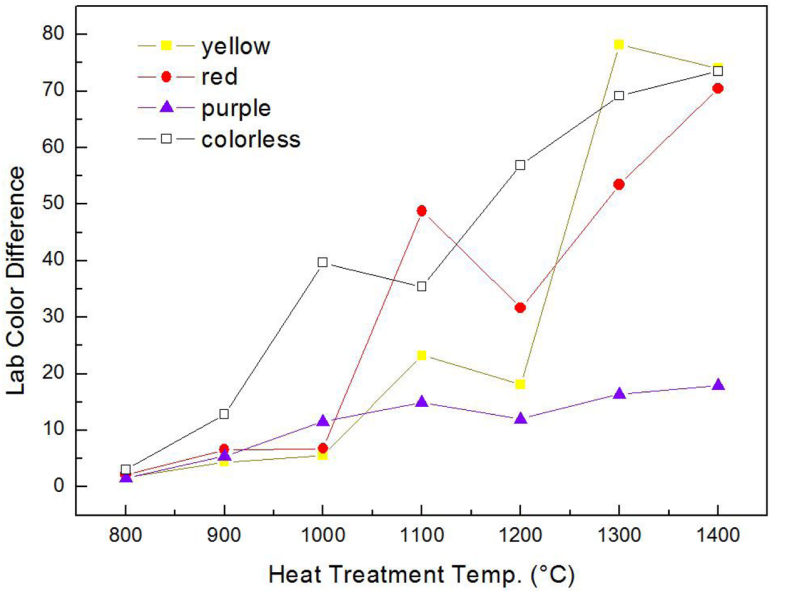

(a)

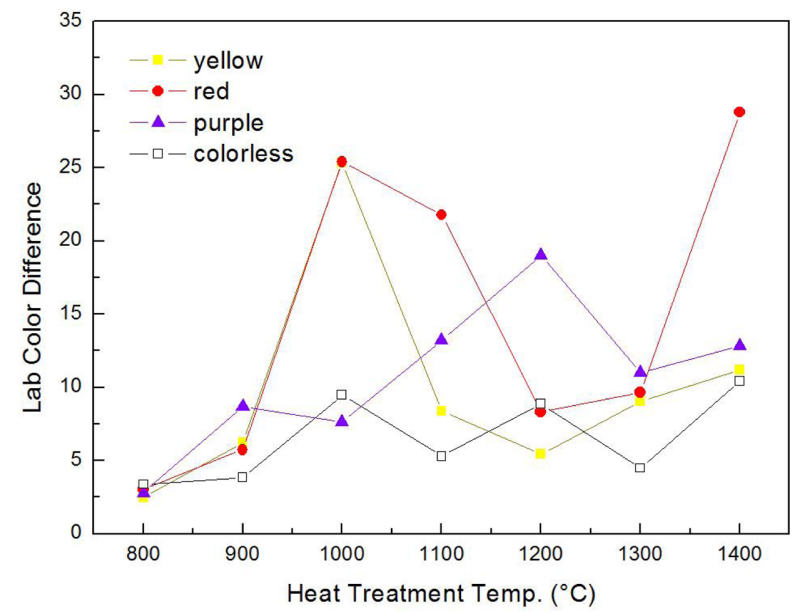

(b)

Fig. 4. The plots of the color difference of CZs with annealing temperature in (a) vacuum, and (b) air atmosphere.

\section{REFERENCES}

1. G. Stapper, M. Bernasconi, N. Nicoloso, and M. Parrinello, "Ab Initio Study of Structural and Electronic Properties of Yttria-Stabilized Cubic Zirconia," Phys. Rev. B, 59 [2] 797 810 (1999).

2. J. Wang and R. Stevens, "Toughening Mechanisms in Duplex Alumina-Zirconia Ceramics," J. Mater. Sci., 23 [3] 804-8 (1988).

3. D. L. Wood and K. Nassau, "Refractive Index of Cubic Zirconia Stabilized with Yttria," Appl. Opt., 21 [16] 2978-81 (1982).

4. H. J. F. Jansen, "Electronic Structure of Cubic and Tetragonal Zirconia," Phys. Rev. B, 43 [9] 7267-78 (1991).

5. J. H. Lee, "Korea Jewelry Market Research 2015," pp. 4344, Aram publishing, Seoul, 2015.

6. S. R. Casolco, J. Xu, and J. E. Garay, "Transparent/Translucent Polycrystalline Nanostructured Yttria Stabilized Zirconia with Varying Colors," Scr. Mater., 58 [6] 516-19 (2008). 
7. R. W. Hesse, Jewerlymaking Through History: An Encyclopedia; pp. 88-9, Greenwood Press, London, 2007.

8. F. Li, Y. Shen, and O. S. Song, "Color Enhancement for Cubic Zirconia with Low Temperature Annealing," $J$. Korea Acad. Industr. Coop. Soc., 11 [4] 1186-91 (2010).

9. Y. Shen, K. J. Nam, and O. S. Song, "A Study on the Color Change Mechanism by Vacuum Annealing in Cubic Zirconia," J. Korea Acad. Industr. Coop. Soc., 11 [10] 3621-25 (2010).

10. S. Murali and V. K. Govindan, "Shadow Detection and Remocal from a Single Image Using Lab Color Space," Bulg. Acad. Sci., 13 [1] 95-103 (2013).

11. I. L. Weatherall and B. D. Coombs, "Skin Color Measurements in Terms of CIELab Color Space Values," J. Invest. Dermatol., 99 [4] 468-73 (1992).

12. L. Jin and D. Li, "A Switching Vector Median Filter Based on the CIELAB Color Space for Color Image Restoration," Signal Process., 87 [6] 1345-54 (2007).

13. A. Bogicevic, C. Wolverton, G. M. Crosbie, and E. B.
Stechel, "Defect Ordering in Aliovalently Doped Cubic Zirconia from First Principles," Phys. Rev. B, 64 [1] 014106 (2001).

14. F. J. Ritzert, H. M. Yun, and R. V. Miner, "Single Crystal Fibers of Yttria-Stabilized Cubic Zirconia with Ternary Oxide Additions," J. Mater. Sci., 33 [22] 5339-49 (1998).

15. F. Guo and P. Xiao, "Effect of $\mathrm{Fe}_{2} \mathrm{O}_{3}$ Doping on Sintering of Yttria-Stabilized Zirconia,” J. Eur. Cera. Soc., 32 [16] 4157 64 (2012).

16. G. A. Gogotsi, S. N. Dub, B. I. Ozerskii, D. Y. Ostrovoi, G. E. Khomenko, E. E. Lomonova, S. K. Batygov, M. A. Vishnyakova, V. F. Kalabukhova, S. V. Lavrishchev, and V. A, Myzina, "Zirconia Crystals with Yttrium and Cerium Oxides," Refract. Ind. Ceram., 36 [7] 199-207 (1995).

17. R. Ianos and R. Lazau, "Chromium-Doped Calcium Zirconate-A Potential Red Shade Pigment: Preparation, Characterization and Testing," Dyes Pigments, 105 152-56 (2014). 